\title{
ASUHAN KEBIDANAN KOMPREHENSIF PADA NY"K" GIII P2101 DENGAN POST DATE DI POLI OBGYNE RSUD Dr. SOEGIRI LAMONGAN TAHUN 2015
}

\author{
Sumiyati* \\ Yuanita Hartiningsih** \\ *Dosen Program Studi Diploma III Kebidanan Universitas Islam Lamongan \\ **Mahasiswa Program Studi Diploma III Kebidanan Universitas Islam Lamongan

\section{RINGKASAN}

Kehamilan (Gravida) post date merupakan usia kehamilan $\geq 42$ minggu. Di Poli Obgyne RSUD Dr. Soegiri Lamongan masih terdapat angka kehamilan post date sebesar 3,6\%. Metode yang dipakai dalam penelitian ini deskriptif observasi yang dilaksanakan dengan pendekatan kohort mulai dari kehamilan sampai kontrasepsi diperoleh melalui wawancara, pengkajian data primer, sekunder, pemeriksaan fisik, penunjang dan dilakukan pendokumentasian standar asuhan kebidanan SOAP. Hasil asuhan kebidanan pada Ny " $K$ " GIII $P_{2 I 0 I}$ dengan post date terdapat kesenjangan pada analisa untuk potensial partus lama, HPP, insufisiensi plasenta tidak terjadi pada tinjauan kasus. Berdasarkan hasil studi kasus diperoleh data bahwa partus lama, HPP tidak selalu menjadi faktor resiko post date. Dampak terhadap ibu akan sering dijumpai seperti partus lama, kesalahan letak, inersia uteri, distosia bahu, robekan luas jalan lahir, insufisiensi plasenta dan perdarahan postpartum. Peran petugas kesehatan dalam upaya mendukung kesehatan ibu hamil post date dengan cara mengoptimalkan dalam pelaksanaan asuhan kebidanan komprehensif pada kehamilan post date dengan manajemen kebidanan SOAP.

\section{Kata Kunci : Post Date, Gravida}

\section{PENDAHULUAN}

Kehamilan post date merupakan kehamilan yang umur kehamilannya lebih dari 42 minggu dan merupakan salah satu kehamilan yang beresiko tinggi, dimana dapat terjadi komplikasi pada ibu dan janin. (Prawirohardjo: 2008). Penyebab pasti belum diketahui, faktor yang dikemukakan antara lain Hormonal, Herediter, Kadar kortisol pada darah bayi yang rendah, Kurangnya air ketuban, Insufiensi plasenta.

Menurut WHO angka kematian ibu merupakan salah satu target yang telah ditentukan dalam tujuan pembangunan milenium (MDGs) ke lima yaitu meningkatkan kesehatan ibu dengan menurunkan angka kematian ibu sebesar tiga per empat antara tahun 1990 - 2015. WHO memperkirakan diseluruh dunia setiap tahun lebih dari 585.000 meninggal saat hamil atau bersalin. Target AKI di Indonesia pada tahun 2015 adalah 102 kematian per 100.000 kelahiran hidup. Sementara itu berdasarkan Survei Demografi dan Kesehatan Indonesia (SDKI) terakhir tahun 2012, Angka Kematian Ibu (AKI) (yang berkaitan dengan kehamilan, persalinan, dan nifas) sebesar 359 per 100.000 
kelahiran hidup. Data yang diperoleh dari Profil kesehatan Jawa Timur tahun 2014 jumlah ibu hamil sebanyak 918.360, dari data tersebut jumlah kasus ibu hamil normal 823.264 kasus (89.64\%), ibu hamil dengan postdate sebanyak 4.921 kasus $(1,67 \%)$ dan sisanya kehamilan dengan kasus-kasus yang lain. Berdasarkan data dari Dinas Kesehatan Kabupaten Lamongan pada tahun 2014 jumlah ibu hamil sebanyak 21.032 orang. Dari data yang diperoleh di dapatkan 1.850 orang $(8,8 \%)$ ibu hamil yang mengalami post date. Pada studi pendahuluan yang dilakukan di Puskesmas Kembangbahu Lamongan tahun 2014 di dapatkan kunjungan ibu hamil sebanyak 717 orang. Dari 717 orang ibu hamil didapatkan16 orang $(2,3 \%)$ post date. Sedangkan data yang diperoleh dari register kunjungan di Poli Obgyne RSUD Dr. Soegiri Lamongan pada bulan Januari - Juni 2015 di dapatkan kunjungan ibu hamil sebanyak 650 orang. Dari 650 orang ibu hamil didapatkan 23 orang $(3,6 \%)$ dengan post date, faktor penyebab kehamilan post date antara lain: 8 orang $(34,8 \%)$ karena paritas, 9 orang $(39,2 \%)$ karena bayi besar, 6 orang $(26,1 \%)$ karena oligohidramnion.

Permasalahan kehamilan post date adalah plasenta tidak sanggup memberikan nutrisi dan pertukaran $\mathrm{CO} 2 / \mathrm{O} 2$ sehingga mempunyai resiko asfiksia, mengakibatkan pertumbuhan janin makin lambat bahkan terjadi kematian dalam rahim, terjadi perubahan metabolisme janin. Air ketuban berkurang dan makin kental bahkan bisa mengering habis. Akibat kurangnya pasokan oksigen, janin bisa buang air besar didalam rahim, yang menyebabkan cairan ketuban berwarna hijau pekat. Sebagian janin bertambah berat sehingga memerlukan tindakan persalinan. Dampak terhadap ibuya itu dapat menyebabkan distosia, karena aksi uterus tidak terkoordinir, janin besar, moulding kepala kurang. Maka akan sering dijumpai seperti partus lama, kesalahan letak, inersia uteri, distosia bahu, robekan luas jalan lahir, dan perdarahan postpartum.

Upaya yang dilakukan dalam kasus kehamilan dengan postdate dengan usia kehamilan >40-42 minggu yang penting monitoring janin sebaik-baiknya. Apabila tidak ada tanda insufisiense plasenta, persalinan spontan dapat ditunggu dengan pengawasan ketat. Lakukan pemeriksaan dalam untuk menilai kematangan serviks, kalau sudah matang boleh dilakukan induksi persalinan dengan atau tanpa amniotomi. Selain itu janin postmatur lebih peka terhadap sedatif dan narkosa. Sebagai bidan dalam menangani kehamilan post date harus memberikan pelayanan ANC (Ante Natal Care) yang berkualitas dan mampu mendeteksi secara dini adanya kehamilan postdate dengan cara menghindari kesalahan menentukan usia kehamilan dalam menghitung HPHT dan tafsiran persalinan serta menganjurkan ibu untuk pemeriksaan USG.

Tujuan penelitian ini adalah mendapat gambaran tentang pelaksanaan Asuhan Kebidanan Komprehensif Pada Ny "K" GIII $\mathrm{P}_{2101}$ dengan Post date di Poli Obgyne RSUD Dr. Soegiri Lamongan Tahun 2015.

PEMBAHASAN

Pengkajian Data Subyektif 
Terdapat persamaan pada data subyektif untuk keluhan utama. Pada teori diterangkan bahwa ibu dengan post date belum ada His dan pengeluaran lendir bercampur darah. Sedangkan pada kasus sendiri kehamilan post date pada Ny " $K$ " belum terdapat tanda-tanda persalinan dengan adanya His,dan pengeluaran lendir bercampur darah.

Kadar kortisol pada darah bayi yang rendah sehingga disimpulkan kerentanan akan stress merupakan faktor tidak timbulnya his.

Normalnya pada kehamilan trimester III akhir hormone progesterone mengalami penurunan sehingga dapat timbul His, Sedangkan pada kehamilan post date hormone progesterone tidak cepat turun, sehingga tidak ada his ataupun tanda-tanda persalinan.

Kadar progesteron tidak cepat turun walaupun kehamilan telah cukup bulan sehingga kepekaan uterus terhadap oksitosin berkurang.

\section{Pengkajian Data Obyektif}

Pada data obyektif terdapat kesamaan untuk pemeriksaan USG tampak jumlah cairan ketuban yang berkurang, pada tinjauan pustaka dijelaskan bahwa pada kehamilan dengan post date terdapat penurunan jumlah cairan ketuban.

Permasalahan kehamilan lewat waktu terjadi perubahan metabolisme janin, jumlah air ketuban berkurang dan makin kental. Kurangnya cairan ketuban akibat dari cairan yang makin mengental pada kehamilan dengan post date sehingga resiko terjadinya asfiksia dan abnormal pada jantung janin.

Air ketuban berkurang dan makin kental, akibat kurangnya pasokan oksigen ke janin bisa buang air besar di dalam rahim yang menyebabkan cairan ketuban berwarna hijau pekat. Cairan ketuban ini dapat terhisap masuk ke dalam pernafasan bayi, sehingga harus segera dihisap keluar agar bayi tidak mengalami gangguan pernafasan. Jika tidak diatasi akan mengakibatkan kematian bayi.

\section{Analisa Data}

Masalah potensial terdapat kesenjangan, pada teori disebutkan resiko tinggi partus lama dan distosia pada persalinan dengan post date Sedangkan pada tinjauan kasus masalah potensial tidak ditemukan masalah resiko tinggi terhadap partus lama dan distosia pada persalinan.

Sebagian kasus post date berat janin makin menurun sirkulasi darah menuju sirkulasi plasenta dapat mengakibatkan pertumbuhan janin makin lambat dan penurunan berat disebut dismatur, sebagian janin bertambah besar sehingga memerlukan tindakan operasi persalinan.

Pada ibu dengan post date dapat mengakibatkan distosia (kesulitan melahirkan) karena aksi uterus tidak terkoordinir dan perdarahan setelah melahirkan.

\section{Penatalaksanaan}

Merupakan pelaksanaan asuhan yang menyeluruh, pada tinjauan pustaka dan tinjauan kasus ditemukan persamaan. Penatalaksanaan yang dilakukan pada kehamilan post date diantaranya menjelaskan pada pasien dan keluarga hasil pemeriksaan, menganjurkan untuk melakukan pemeriksaan labolatorium dan USG, melakukan inform consent, menganjurkan pasien untuk memenuhi kebutuhan nutrisi, kolaborasi dengan Dokter SPOG 
untuk memberikan antibiotik serta melakukan induksi persalinan.

Pada tinjauan kasus post date dalam penatalaksanaan memerlukan TTV dan CHPB untuk memantau keadaan umum ibu dan kesejahteraan janin, menyebutkan pada penatalaksanaan kehamilan dengan post date dilakukan pemeriksaan USG, menganjurkan pasien untuk memenuhi kebutuhan nutrisi, serta tindakan induksi persalinan.

Setelah usia kehamilan $\geq 40$ minggu yang penting adalah monitoring janin sebaik-baiknya, dengan dilakukan pemeriksaan dalam untuk menilai kematangan servix, jika sudah matang dapat diberikan oxytosin drip untuk merangsang kontraksi, jika servik belum matang dan terdapat komplikasi dari ibu maupun janin direncanakan untuk sectio sesarea. Pemeriksaan dalam untuk menilai kematangan serviks, kalau matang boleh dilakukan induksi persalinan dengan atau tanpa amniotomi.

Tindakan operasi Sectio Cesarea dapat dipertimbangkan pada insufisiensi plasenta dengan keadaan serviks belum matang, pembukaan belum lengkap,persalinan lama, terjadi gawat janin, primigravida tua, kematian janin dalam kandungan, pre-eklamsia, hipertensi menahun, infertilisasi, kesalahan letak janin.

\section{KESIMPULAN}

\section{Simpulan}

Pada kesimpulan didapatkan data melalui data Subyektif, data Obyektif, analisa dan penatalaksanaan. Pada pengkajian subjektif terdapat persamaan pada keluhan utama dalam hal belum adanya his serta pengeluaran lendir bercampur darah pada kasus post date. Pada pengkajian objektif terdapat persamaan pada pemeriksaan USG dalam hal jumlah cairan ketuban yang berkurang pada kasus post date. Pada analisa terdapat kesenjangan pada masalah potensial dalam hal ibu mengalami partus lama dan distosia pada kasus post date. Pada penatalaksanaan terdapat persamaan pada tinjauan teori dan tinjauan kasus dalam hal penatalaksanaan kehamilan dengan post date dan catatan perkembangan.

\section{Saran}

Pemahaman tentang informasi yang berhubungan dengan post date akan membantu masyarakat dalam mendeteksi dini komplikasi dan tindakan yang harus dilakukan agar tidak terjadi hal yang tidak diinginkan.

\section{DAFTAR PUSTAKA}

Mochtar, Rustam. 2008. Sinopsis Obstetri: obstetri fisiologi, obstetri patologi. Jakarta: EGC.

Prawirohardjo, Sarwono. 2009. ilmu kebidanan. Jakarta : YBP-SP

Prawiroharjo, Sarwono. 2010. Ilmu Kebidanan. Jakarta : PT. Bina Pustaka Sarwono Prawiroharjo. Prof.dr Manuaba Ida Bagus Gde. Ilmu Kebidanan, 2009 Penyakit Kandungan dan Keluarga Berencana Untuk Pendidikan Bidan. DSOG/Penerbit Buku Kedokteran, Jakarta,EGC

Rukiyah, Yeyeh \& Yulianti, Lia. 2010. Asuhan Kebidanan IV (Patologi Kebidanan). Jakarta : Trans Info Media.

Saifuddin, Abdul Bari, dkk. 2010. Buku Acuan Nasional
Pelayanan Kesehatan
Maternal dan Neonatal. 
Jakarta: Yayasan Bina Pustaka Sarwono Prawirohardjo.

Varney Hellen\& Kriebs Jan M. 2002.

Asuhan Kebidanan. Jakarta

(http:/organisasikesehatandunia

.com/tanggal 27 Maret 2014)

www.datastatistik-indonesia.com

(http//tribunnews.com) 
